\title{
Effect of Thyme aqueous and alcoholic extract on the Beef Mincemeat shelf life extension
}

\section{Khawlah Abdallah Salman ${ }^{1 *}$, Hussein Ali Hussein ${ }^{1}$, Ohood Aqeed Radhi ${ }^{2}$, Ali Rasool Assai ${ }^{1}$}

${ }^{1}$ Faculty of Agriculture, Department of Food Sciences, University of Kufa, Iraq

${ }^{2}$ Faculty of Nursing, Department of Basic Sciences, University of Kufa, Iraq

Received - December 14, 2021; Revision - January 28, 2022; Accepted - February 19, 2022

Available Online - February 28, 2022

DOI: http://dx.doi.org/10.18006/2022.10(1).124.130

\section{KEYWORDS}

Thyme

Aqueous and alcoholic extracts

Mincemeat

Antibacterial activity

\begin{abstract}
Antioxidant and antimicrobial activity of thyme has been well established against various microorganisms. This study was carried out to investigate the effect of aqueous and alcoholic extract of thyme on beef mincemeat quality. Three differential concentrations $(0.4,0.8$, and $1.2 \mathrm{mg} / \mathrm{ml})$ of both thyme extracts were used for the beef mincemeat preservation. Untreated meat samples were considered as the control group while the extracts treated beef mincemeat are stored at $4^{\circ} \mathrm{C}$ for 7 to 14 days. To validate the extract's ability to prolong the storage period at $4{ }^{\circ} \mathrm{C}$, various bacteriological indicators like total plate count, presence of total coliform, Salmonella, Shigella, and Staphylococcus aureus count were assessed. The results of the antimicrobial assay of aqueous and alcoholic extracts of thyme at different concentrations showed that the aqueous extract had significant inhibitory action on the growth of a wide range of bacteria compared to the alcoholic extract. Thus, the thyme aqueous extracts can be efficient and promising as preservatives for meat and its products, especially at high concentrations to inhibit bacterial growth.
\end{abstract}

* Corresponding author

E-mail: khawla.alzurfi@uokufa.edu.iq (Khawlah Abdallah Salman)

Peer review under responsibility of Journal of Experimental Biology and Agricultural Sciences.

Production and Hosting by Horizon Publisher India [HPI] (http://www.horizonpublisherindia.in/).

All rights reserved.
All the articles published by Journal of Experimental Biology and Agricultural Sciences are licensed under a Creative Commons Attribution-NonCommercial 4.0 International License Based on a work at www.jebas.org.

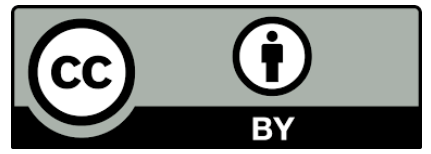




\section{Introduction}

Biochemical changes and enhanced microbial activity are the most common events that occur during food spoilage, especially in the case of inadequate preparation, handling, packaging, and storage (Tshabalala et al. 2021). Many factors such as lipid peroxidation may encourage worsening the food quality and safety as a result of the formation of hydroperoxides (Fratianni et al. 2010). Peroxidation may further cause the deterioration and degeneration of other secondary products (Djordjevi et al. 2019). Undeniably, refrigerated delivery has made the international supply of consumable foods feasible. However, proper packaging conditions and refrigeration are not always sufficient to secure the food from spoilage, contamination, and undesirable changes (Fratianni et al. 2010). Perishable types of food, such as meat, spoil easily due to the favorable growth conditions for various microorganisms. Besides this, many undesirable chemical and enzymatic activities lead to unpleasant odors and an unacceptable taste (Djordjevi et al. 2019) which make food unsuitable for human consumption (Vencato et al. 2020). Since ancient times, people used various traditional preservation methods such as salting, drying, smoking, fermentation, and canning whose primary function was to limit decay and rottenness (Zengin and Baysal 2014). These methods are also used to prevent meat spoilage and prolong its shelf life (Hernández et al 2018). Recently, various advanced methods such as refrigeration, freezing, and chemical preservation have been directed towards preserving food without affecting its flavor, nutritional quality, and texture (Zengin and Baysal 2014). Chemical preservation is an artificial method that is based on applying some chemicals such as nitrates, benzoates, sulfites, and sorbates for preservation (Ukrainets 2016). It is well established that these chemical preservatives have a negative effect on human health owing to their allergic and carcinogenic causes if they are used or consumed excessively (Mischek and Krapfenbauer-Cermak 2011). Therefore, there is an urgent need of replacing these chemical preservatives with natural products (based on herbs and medicinal plants as food additives). Various researches establish that natural preservatives can be used as an alternative to enhance food quality without altering food taste (Ukrainets 2016). Antimicrobial and antioxidant activities of natural derivatives against food spoiling microbes have been reported by various researchers (Ukrainets 2016; Emeka and Chiamaka 2020; Efenberger-Szmechtyk et al. 2020; Pateiro et al. 2021; Salman et al. 2021a), these antimicrobial and antioxidant activities are associated with the content of bioactive natural compounds that are present in these plants (Salman et al. 2021b). Further, these natural additives have proven their ability and effectiveness to reduce the effects of oxidative damage, delay in the emergence of objectionable flavors, and improve the food status (color of meat dyes) (EfenbergerSzmechtyk et al. 2020). Therefore, professional interest in studying the properties of these natural food additives has increased considerably.
Thyme is one of the bioactive herbs used as culinary (flavoring agent and spice) and therapeutically agent (Garca-Dez et al. 2017). Plant extract of thyme contains many active ingredients such as monoterpene phenols, carvacrol, thymol, p-cymene, and other monoterpenes, such as -pinene, 1,8-cineole, camphor, linalool, and borneol which might attribute the medical effect of the plant. (Emeka and Chiamaka 2020). Further, thyme's antibacterial properties were notably established against pathogenic bacteria (Wesolowska and Jadczak 2019).

The addition of thyme essential oil to dried meat products showed bacterial inhibition activity against foodborne pathogens and it was similar to the other selected essential oils (Garca-Dez et al. 2017). Agrimonti et al. (2019) investigated the antimicrobial synergetic effect of various essential oils including cinnamon, thyme, and oregano against a wider range of microorganisms and reported that the thyme components have significant microbial inhibition, especially against the relatively resistant gram-negative. Robust action of thymol and carvacrol against $P$. aeruginosa or $S$. aureus has been also reported by Di Pasqua et al. (2006). These plant extracts inhibit the growth of many microorganisms by desolating the plasma membrane, disturbing the $\mathrm{pH}$, and misbalancing the inorganic materials (Agrimonti et al. 2019, Nieto 2020, Yang et al. 2021). Thus, there is a possibility to increase the quality of meat and decrease microbial deterioration by using plant extracts. Therefore, the current study was conducted to investigate the potential role of thyme aqueous and alcoholic extracts as a preservative agent to prolong the shelf life of mincemeat by the inhibition of bacterial growth.

\section{Materials and Methods}

\subsection{Preparation of thyme extracts}

Thyme leaves were procured from the local markets of Al-Najaf province, Iraq. Collected leaves were washed using tap water, followed by using sterile water. The dried plant's leaves were crushed immediately before the assay using an electric grinder, followed by grinding. Alcoholic extracts of collected thyme leaf were prepared by adding $100 \mathrm{gm}$ of the leaves powder to $1000 \mathrm{ml}$ of $70 \%(\mathrm{v} / \mathrm{v})$ aqueous ethanol in a closed conical flask for $24 \mathrm{hrs}$ at room temperature in the dark. The extract was filtered through cheesecloth, and the residue was re-extracted three times using the same solvent. The filtrate obtained was evaporated in a vacuum evaporator at $40{ }^{\circ} \mathrm{C}$ and stored at lower temperature till the completion of the study. The test extracts solution was prepared from the stock solution by dissolving the required amount of ethanol and the concentration was set $0.4,0.8$.and $1.2 \mathrm{mg} / \mathrm{ml}$. Similarly, the aqueous extracts were prepared by adding $100 \mathrm{~g}$ of ground sample to $1000 \mathrm{ml}$ of sterilized water and leaving for 30 minutes on a magnetic stirrer, followed by filtering using cheesecloth. The obtained filtrate was evaporated in a vacuum 
evaporator at $40{ }^{\circ} \mathrm{C}$ and frozen until used. The concentrations were prepared as mentioned previously as the alcoholic extracts.

\subsection{Preparation of mincemeat samples}

Samples of beef meat were procured from local markets in AlNajaf, Iraq, and transferred to the laboratory for processing. The samples were cut into pieces and then minced using a meat grinder. From the prepared samples, the first $250 \mathrm{gm}$ of mincemeat sample was stored as a control sample without any extract additives. The remaining samples were divided into six different parts (250 grams for each concentration) and treated with the $0.4,0.8$, and 1.2 percent aqueous and ethanol extracts of thyme.

\subsection{Microbial Count}

Microbiological analysis was performed using the plate counting technique. The microbial count was carried out as per the recommendation of the American Public Health Association for food examination (APHA 1992). The analysis was based on counting the TPC, coliform bacteria, Salmonella, Shigella, and Staphylococcus aureus. Nutrient agar was employed for TPC. As per the bacterial strains, the culture medium was changed and McConkey agar medium was used for the determination of coliform bacteria, S.S. agar was used for the investigation of Salmonella- Shigella, and MSA for counting $S$. aureus. Homogenized samples (extracts with the mincemeat) were serially diluted up to 10-fold and dilutions D4, D5, and D6 were selected for the bacterial isolation and placed in a sterilized petri dish. The plates were performed in triplicates and incubated at $37^{\circ} \mathrm{C}$ for 24 48 hours on the days specified in the research schedule (7 days-14 days). Based on the selective media and morphological characterization the strains of bacteria were identified and calculated.

\subsection{Statistical Analysis}

All the obtained results were expressed in mean \pm SD (standard deviation) in this study. Differences between means of data were compared by the least significant difference (LSD) calculated by using the Statistical Analysis System (SAS Institute, Inc., Cary, NC).

\section{Results}

The results of an antibacterial assay of the aqueous and alcoholic extracts of thyme on the bacterial reduction count were evaluated and represented by figures 1-4. The mincemeat samples were stored at $4{ }^{\circ} \mathrm{C}$ and observations were taken after 7 and 14 days of storage for different concentrations (D 4, D5, and D6). Results presented in figure 1 revealed the effect of various aqueous (TW) and alcoholic extracts (TA) concentrations on the total bacterial count after 7 days of culture. A significant effect of both thyme extracts was reported on the total bacterial count and meat samples treated by thyme extract have significantly lower bacterial colony count as compared to the untreated control samples. Further, a gradual reduction was reported with increasing concentrations and the least bacterial count was reported when samples were treated by high concentration $(1.2 \mathrm{mg} / \mathrm{ml})$, particularly in the case of aqueous extracts (TW). The growth reduction was variable between the dilutions of meat samples (D4-D6) and it was reported highest in D6 for both types of extracts. After 7 days of the treatments, the least bacterial growth was reported for coliform bacteria, Salmonella, Shigella, and S.aureus as compared to the

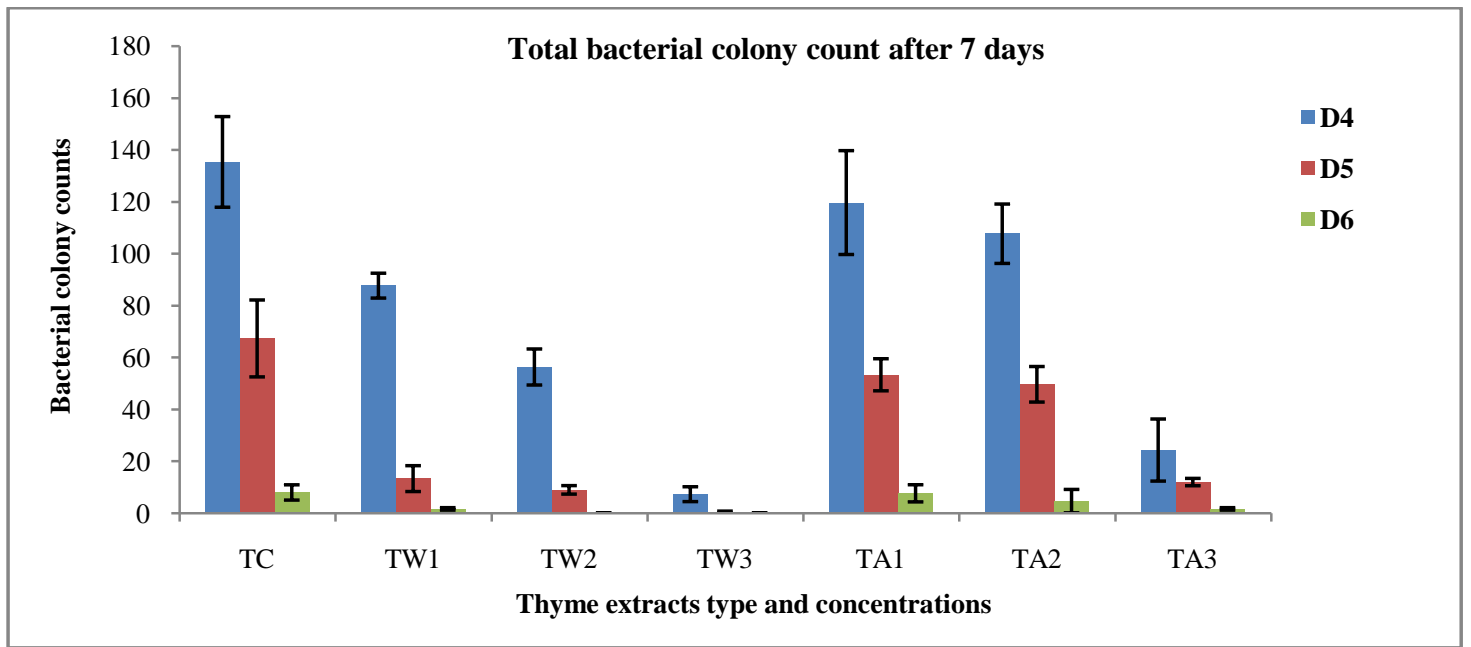

Figure 1 Effect of aqueous and alcoholic thyme extracts on the total bacterial colony count at different concentrations and dilutions on day 7 of storage at $4^{\circ} \mathrm{C}$. Values given in bars are mean of count, the error bars represent the SD (standard deviation); TC (control); TW1-TW3 $(0.4 \mathrm{mg} / \mathrm{ml}, 0.8 \mathrm{mg} / \mathrm{ml}$, and $1.2 \mathrm{mg} / \mathrm{ml}$ aqueous extracts respectively); TA1-TA3 $(0.4 \mathrm{mg} / \mathrm{ml}, 0.8 \mathrm{mg} / \mathrm{ml}$, and $1.2 \mathrm{mg} / \mathrm{ml}$ ethanol extracts respectively); D4-D6 (Dilutions of the cultured samples) 


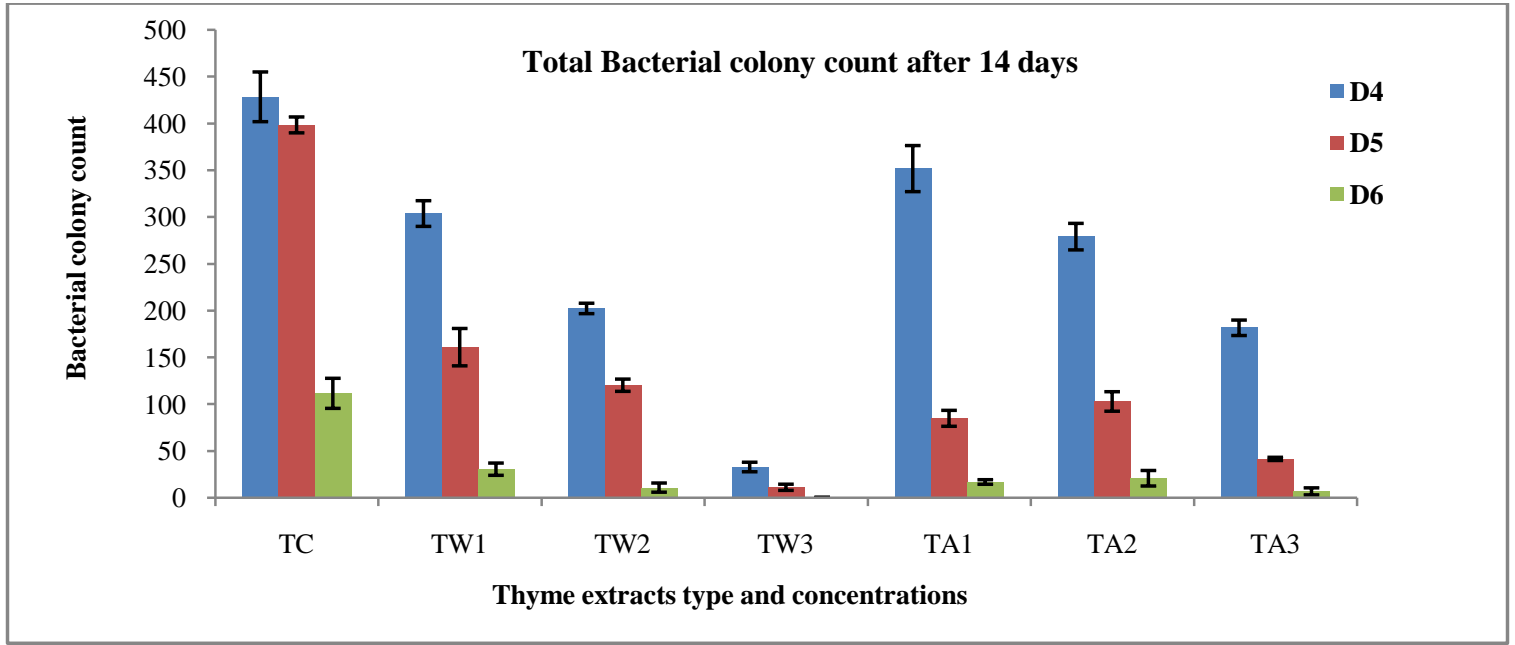

Figure 2 Effect of aqueous and alcoholic thyme extracts on the total bacterial colony count at different concentrations and dilutions on day 14 of storage at $4^{\circ} \mathrm{C}$ (Values given in bars are mean of count, reset all figure legends and abbreviations are similar to the figure 1)

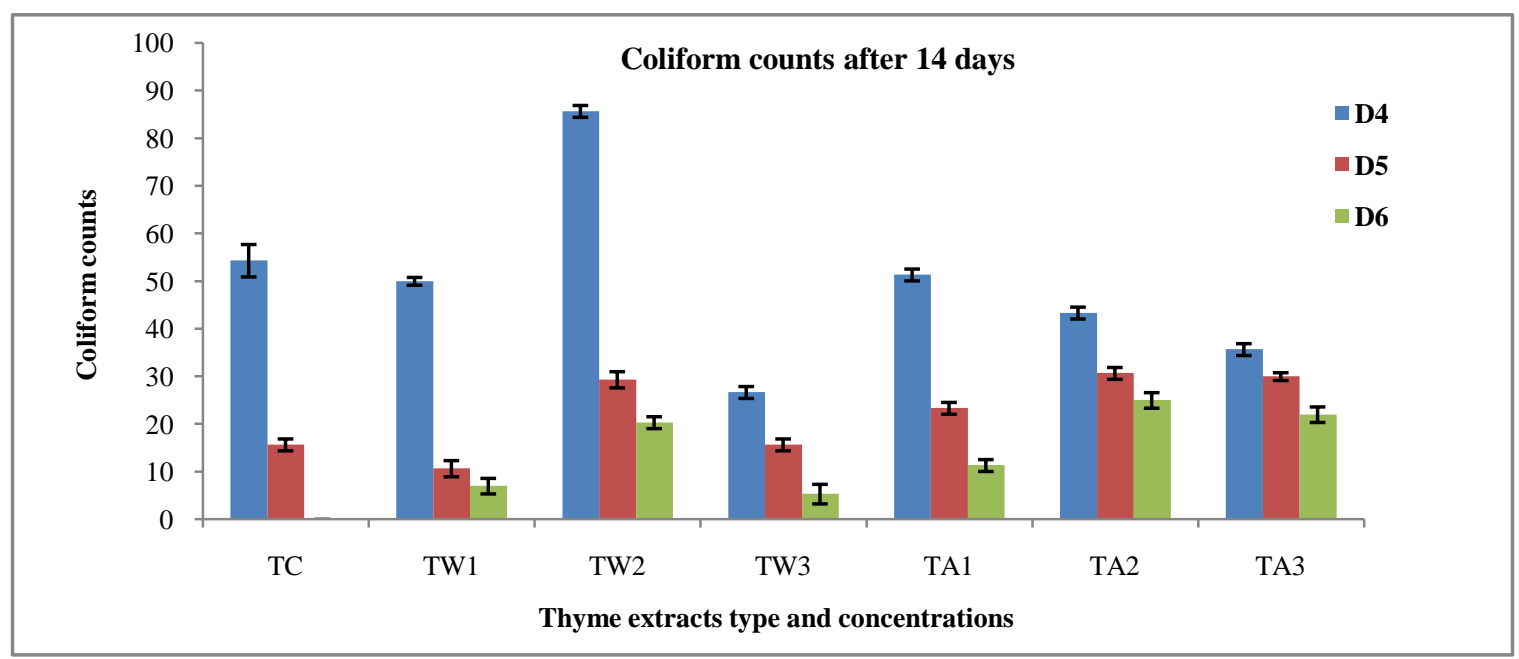

Figure 3 Effect of aqueous and alcoholic thyme extracts on the coliform bacterial counts at different concentrations and dilutions on day 14 of storage at $4^{\circ} \mathrm{C}$ (Values given in bars are mean of count, reset all figure legends and abbreviations are similar to the figure 1)

control. On $14^{\text {th }}$ day of storage the total bacterial count was dramatically increased as compared to the 7 days of storage (Figure 2). However, a significant decline $(\mathrm{P}<0.05)$ was reported at the concentration $1.2 \mathrm{mg} / \mathrm{ml}$ and D6 in aqueous extracts compared to the control.

After 14 days of storage, in the case of coliform bacterial count variable results were reported which are not following any predetermined pattern. Among the tested aqueous extract concentration, the least coliform count was reported from the lowest concentration (TW1), this was followed by the highest concentration (TW1) while concentration TW2 appeared to be less efficient in reducing the number of coliform bacteria colonies count. In the case of alcoholic extracts, there were statistically significant differences were identified $(\mathrm{P}>0.05)$ between the concentrations and examined sample dilutions. However, there are significant differences $(\mathrm{P}>0.05)$ recorded between the control and both extracts but interestingly no coliform was observed at D6 in the control (Figure 3).

Further, in the case of Salmonella and Shigella count, aqueous and alcoholic extracts were not showing any significant difference $(\mathrm{P}>$ 0.05 ) between the various concentrations, dilutions, and control treatments. Among the tested concentrations and dilutions, treatment TW3 was found effective in reducing the count of Salmonella and Shigella (Figure 4). Whereas in the case of S.aureus, no bacterial growth was reported between variations concentrations and dilutions, and the highest S.aureus growth was reported from the control treatments at lowest sample dilutions (Figure 5). 


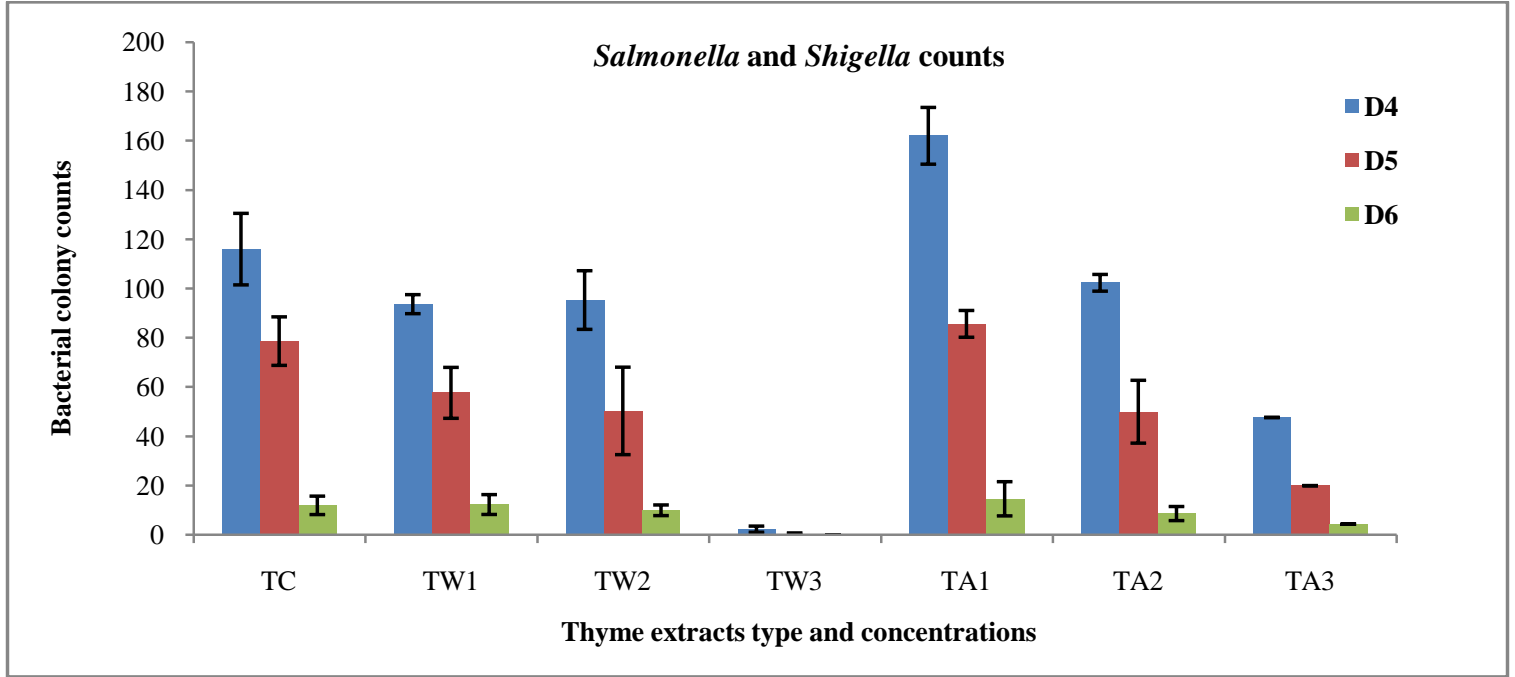

Figure 4 Effect of aqueous and alcoholic thyme extracts on the Salmonella and Shigella counts at different concentrations and dilutions on day 14 of storage at $4^{\circ} \mathrm{C}$ (Values given in bars are mean of count, reset all figure legends and abbreviations are similar to the figure 1)

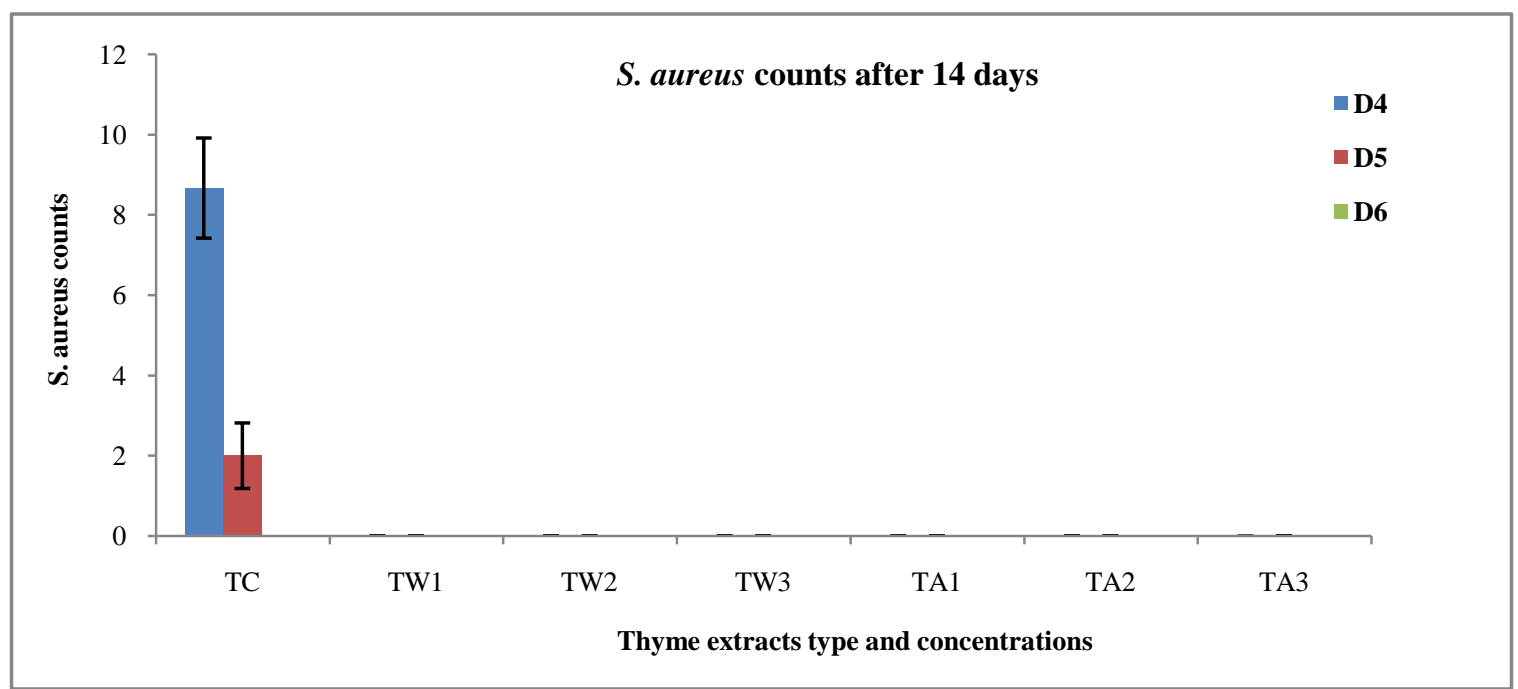

Figure 5 Effect of aqueous and alcoholic thyme extracts on the S.aureus counts at different concentrations and dilutions on day 14 of storage at $4^{\circ} \mathrm{C}$ (Values given in bars are mean of count, reset all figure legends and abbreviations are similar to the figure 1)

\section{Discussion}

One of the most important obstacles to food manufacturers in the presence of various harmful microbes that may deteriorate the food during storage and transportation. Increasing the human concern regarding the harmful effect of chemical preservatives, generate the need to explore plant-based natural preservatives (Nieto 2020). These natural food preservatives that have been traditionally applied for preservative purposes are safe, cost-effective, and also appetite boosters (Ali et al. 2018). The antimicrobial activity of various plant extracts against foodborne pathogens has been well explored (Garca-Dez et al. 2017; Ali et al. 2018; Agrimonti et al. 2019; Salman et al. 2021b).
Thyme is one of the most popular herbs in the food industry due to its flavor, fragrance qualities, and medicinal properties. In the current study, the efficiency of two solvent extracts (aqueous and alcoholic) was evaluated for their antibacterial action on cooled mincemeat samples during different periods (7 and 14 days). Furthermore, different gradual concentrations were applied, and the results on the seventh day of storage showed that with increasing the extract concentration, the total viable count of bacteria was reduced, in particular of D6 dilution and aqueous extracts (TW) in comparison with the non-treated samples. However, on day 14 of storage, the total plate count was slightly increased, but the number was reduced again at D6 serial dilution and aqueous extract (TW), especially for the highest concentration 
$(1.2 \mathrm{mg} / \mathrm{ml})$. Among the tested solvents, the aqueous extract was found superior over the alcoholic extract and this might be due to the polar nature of most active ingredients, these components are competently dissolved in water and they retain their actions against the bacterial selected parameters (Abubakar and Haque 2020). Despite the safety and no toxicity effects involved with water extracts, water is not sufficient as a solvent. Therefore, different solvents (semi-polar and non-polar) are applied instead to ensure the bioavailability of the active constituents. Correspondingly, Hernández et al. (2018) recorded that viable counts significantly decreased when they applied thyme essential oils to prolong the shelf-life of dried meat. Undoubtedly, thyme is well-known to possess pharmacological relevance, and the presence of rich bioactive content may interfere with and disturbed bacterial growth (Nieto 2020).

The results of the test for coliform bacteria revealed that no growth was observed on the seventh day of storage. However, when the period was extended to 14 days, the situation was slightly different. The bacterial growth was observed at all concentrations and dilutions but in different manners. The results of the current study are in agreement with the findings of Boskovic et al. (2015), those who investigate the effect of some thyme constituents against a range of coliform bacteria and obtained similar results. Similarly, Duckova et al. (2012) reported the bactericidal effects of thyme oil at a concentration of $0.05 \%$ against E. faecalis and E. mundtii strains at 6 and $25{ }^{\circ} \mathrm{C}$ storage. Therefore, these outcomes can be explained by the impact of the natural extracts on the collapse of negative bacteria cell walls, these extracts also deplete the lipopolysaccharides and increase the permeability of the cytoplasmic membrane for ATP and some ions, which facilitated cell death (Boskovic et al. 2015). Trajchev et al. (2020) also evaluated the bactericidal efficacy of some medicinal plant extracts including thyme against the Salmonella spp. that are resistant to the majority of commercial antibiotics and are reported that thyme extract exhibited the most killing efficacy against the Salmonella spp. Additionally, the results of the current study suggested that aqueous extracts increase the bioavailability of active components and completely inhibited the growth of S.aureus on day 14 at all concentrations and dilutions. It is also well established that some pathogens, including S. aureus, S. enterica, and S. typhimurium are sensitive to thymol and carvacrol, and their biocidal action results in fundamental and functional membrane disintegration(Chouhan et al. 2017). Moreover, thyme has also proved its potential in vitro antibacterial activity against food pathogens such as Salmonella, S.aureus, E. coli, Klebsiella, Pseudomonas, and Enterococcus at different concentrations (Boruga et al. 2014).

\section{Conclusion}

From the current research, it could be concluded that the aqueous extracts of thyme can preserve mincemeat from different bacterial contaminants. Therefore, these natural additives could be safely used by meat processors to improve the quality and extend the shelf life of meat products. Obviously, plant extracts prepared from different plant parts are rich in bioactive materials. Hence, they offer excellent substitute agents of synthetic antibacterial. According to the results, there are potential and promising applications of these materials as preservatives for preventing the spoilage and deterioration of different types of meat and meat products. Although these extracts are safe and accessible, further research is needed to investigate their effects on the sensory and nutritional quality of meat products.

\section{Conflict of Interests}

The authors declare that there is no conflict of interest

\section{References}

Abubakar, A., \& Haque, M. (2020). Preparation of medicinal plants: Basic extraction and fractionation procedures for experimental purposes. Journal of Pharmacy and Bioallied Sciences, 12, 1-10.

Agrimonti, C., White, J., Tonetti, S., \& Marmiroli, N. (2019). Antimicrobial activity of cellulosic pads amended with emulsions of essential oils of oregano, thyme and cinnamon against microorganisms in minced beef meat. International Journal of Food Microbiology, 305, 108246-108256

Ali, F., Abdel-Atty, N., \& Helmy, E. (2018). Improving the quality and extending the shelf life of chilled fresh sausages using natural additives and their extracts. Journal of Microbiology, Biotechnology and Food Sciences, 7, 580-585.

American Public Health Association. (1992). Compendium methods for the microbiological examination of foods, 2nd (ed.), Washington. D.C.

Boruga, O., Jianu, C., Misca, C., Golet, I., Gruia, A.T., \& Horhat, F.G. (2014). Thymus vulgaris essential oil: chemical composition and antimicrobial activity. Journal of Medicine Life, 7, 56-60.

Boskovic, M., Zdravkovic, N., Ivanovic, J., Janjic, J., et al. (2015). Antimicrobial Activity of Thyme (Thymus vulgaris) and Oregano (Origanum vulgare) Essential Oils against Some Food-borne Microorganisms. Procedia Food Science, 5, 18-21.

Chouhan, S., Sharma, K., \& Guleria, S. (2017). Antimicrobial Activity of Some Essential Oils-Present Status and Future Perspectives. Medicines, 4, 1-21.

Di Pasqua, R., Hoskins, N., Betts, G. \& Mauriello, G. (2006). Changes in Membrane Fatty Acids Composition of Microbial Cells Induced by Addiction of Thymol, Carvacrol, Limonene, 
Cinnamaldehyde, and Eugenol in the Growing Media. Journal of Agricultural and Food Chemistry, 54, 2745-2749.

Djordjević, J., Bošković, M., Brankovićlazić, I., djordjević, V., et al. (2019). Spoilage-related bacteria of pork and beef minced meat under vacuum and modified atmosphere. Romanian Biotechnological Letters, 24, 658-668.

Duckova, V., Čanigová, M., Kročko, M., \& Bezeková, J. ( 2012). Antibacterial activity of thyme and rosemary essential oil against enterococci isolated from meat. Potravinarstvo, 6 (1), 10-13.

Efenberger-Szmechtyk, M., Nowak, A., \& Czyzowska, A. (2020). Plant extracts rich in polyphenols: antibacterial agents and natural preservatives for meat and meat products. Critical Reviews in Food Science and Nutrition, 61, 149-178.

Emeka, I., \& Chiamaka, U. (2020). Antibacterial Activity of Abrus precatorius (Linn.) Leaf Extract Against Multi-resistant Wound Bacterial Isolates. Research Journal of Medicinal Plants, 14, 88-95.

Fratianni, F., De Martino, L., Melone, A., De Feo, V., Coppola, R., \& Nazzaro, F. ( 2010). Preservation of Chicken Breast Meat Treated with Thyme and Balm Essential Oils. Journal of Food Science, 75, 528-M535.

García-Díez, J., Alheiro, J., Pinto, A., Falco, V., Fraqueza, M. \& Patarata, L. ( 2017). Synergistic Activity of Essential Oils from Herbs and Spices Used on Meat Products against Food-Borne Pathogens. Natural Product Communications, 12, 281-286.

Hernández, H., Fraňková, A., Klouček, P. \& Banout, J. (2018). The Effect of the Application of Thyme Essential Oil on Microbial Load During Meat Drying. Journal of Visualized Experiments, 133, $1-7$.

Mischek, D., \& Krapfenbauer-Cermak, C. (2011). Exposure assessment of food preservatives (sulfites, benzoic and sorbic acid) in Austria. Food Additives \& Contaminants: Part, 29, 371-382.

Nieto, G. (2020). A Review on Applications and Uses of Thymus in the Food Industry. Plants, 9, 1-29.

Pateiro, M., Gómez-Salazar, J., Jaime-Patlán, M., Sosa-Morales, M., \& Lorenzo, J. (2021). Plant Extracts Obtained with Green
Solvents as Natural Antioxidants in Fresh Meat Products. Antioxidants, 10, 1- 21.

Salman, K., Hussein, A., \& Abbas, S. (2021b). Antifungal activity of chitosan against Rhizopus stolonifer. Journal of Experimental Biology and Agricultural Sciences, 9, 901-906.

Salman, K., Jawad, S., Chafat, N., \& Al-Bdery, A. (2021a). Efficacy of Bark (Juglans regia L.) Extracts Against Periodontitis Bacteria: an In Vitro Study. Indian Journal of Forensic Medicine \& Toxicology, 15, 5492-5498.

Trajchev, M., Stojiljkovic, J., Nakov, D., Glavash Dodov, M., \& Petrovska, M. (2020). In vitro antimicrobial properties of basil and thyme essential oils against Salmonella spp. Macedonian Pharmaceutical Bulletin, 66, 1-8.

Tshabalala, R., Kabelinde, A., Kaptchouang, C., Ateba, C., \& Manganyi, M. (2021). Effect of Clove (Syzygium aromaticum) spice as a microbial inhibitor of resistant bacteria and Organoleptic Quality of meat. Saudi Journal of Biological Sciences, 28, 38553863.

Ukrainets, A. (2016). Antioxidant plant extracts in the meat processing industry. Biotechnologia Acta, 9, 19-27.

Vencato, A., Nickel, V., Silva, M., Kindlein, 1., Bergmann, G., \& Avancini, C. (2020). Salt and crude plant extract as preservatives in a meat model system (ground pork shoulder). Revista Caatinga, $33,562-570$.

Wesolowska, A., \& Jadczak, D. (2019). Comparison of the Chemical Composition of Essential Oils Isolated from Two Thyme (Thymus vulgaris L.) Cultivars. Notulae Botanicae Horti Agrobotanici Cluj-Napoca, 47, 829-835.

Yang, S., Yusoff, K., Ajat, M., Wee, C., et al. (2021). Combinatorial Antimicrobial Efficacy and Mechanism of Linalool Against Clinically Relevant Klebsiella pneumonia. Frontiers in Microbiology, 12, 635016. doi: 10.3389/fmicb.2021.635016.

Zengin, H., \& Baysal, A. ( 2014). Antioxidant and Antimicrobial Activities of Thyme and Clove Essential Oils and Application in Minced Beef. Journal of Food Processing and Preservation, 39, 1261-1271. 